\title{
Case Report on Bilateral Choroidal Tubercles in Tuberculous Meningitis
} Dr. Mamta Bijarnia ${ }^{1}$, Dr. Isha Lohmror ${ }^{2 *}$

${ }^{1}$ Post Graduate Student, Upgraded Department of Ophthalmology, SMS Medical College and Hospital, Jaipur, Rajasthan, India

${ }^{2}$ Senior Resident, Upgraded Department of Ophthalmology, SMS Medical College and Hospital, Jaipur, Rajasthan, India

DOI: $\underline{10.36347 / \text { sjmcr.2020.v08i05.013 }}$

| Received: 09.05.2020 | Accepted: 16.05.2020 | Published: 19.05.2020

*Corresponding author: Dr. Isha Lohmror

Abstract

Choroidal tubercles are considered pathognomonic of milliary tuberculosis. This case highlights the fact that it can also be present in cases of isolated tuberculous meningitis without any pulmonary or systemic features and early diagnosis and prompt treatment helps resolve the lesion completely.

Keywords: Choroidal Tubercles, Tuberculous Meningitis, Anti Tubercular Treatment.

Copyright @ 2020: This is an open-access article distributed under the terms of the Creative Commons Attribution license which permits unrestricted use, distribution, and reproduction in any medium for non-commercial use (NonCommercial, or CC-BY-NC) provided the original author and source are credited.

\section{INTRODUCTION}

Ocular tuberculosis occurs in about $1 \%$ to $2 \%$ of patients with tuberculosis [1] and can involve any tissue of the eye and orbit. The most common clinical presentation of intraocular tuberculosis is multifocal choroiditis [2], manifesting as choroidal tubercles, choroidal tuberculoma, serpiginous like choroiditis and subretinal abscess. Clinically, the tubercles appear as small nodules, usually less than five in number, may be unilateral or bilateral, greyish white-to-yellow in colour with indistinct borders. Fundus angiography exhibits hypofluorescence in early stages and hyperfluorescence in later stages. Active choroidal tubercles involving macula usually presents with visual loss, peripherally situated tubercles are asymptomatic. The healed lesions show atrophic areas with variable pigmentation.

Choroidal tubercles are considered highly specific for miliary tuberculosis. However, its presence without the evidence of miliary tuberculosis is rare and has been reported in very few studies in literature $[3,4]$.

We report a case of choroidal tubercles in association with isolated tuberculous meningitis who had no systemic features of miliary tuberculosis. The purpose of presentation is to give stress on their importance in being easily accessible, appear early in the course of illness thus aids in early diagnosis and treatment. Delayed diagnosis can lead to pain, poor visual prognosis and systemic complications of the infection.

\section{Case Report}

A 35-year-old woman presented in Upgraded Department of Ophthalmology, SMS Medical College \& Hospital, Jaipur with chief complaint of sudden diminution of vision in her left eye since 4-5 days. She gave a past history of hospitalization 2 months back for complaints of fever, headache, vomiting and altered sensorium and was diagnosed with tuberculous meningitis. She was put on antitubercular treatment, to which she responded and discharged after 7 days.

On eye examination, her best corrected visual acuity for left eye was finger count 1 feet for distance with no acceptance on refraction. Right eye distance vision was $6 / 9$ with N6 which improved to $6 / 6$ with $0.5 \mathrm{DC}$ at 15 degree. Intraocular pressure on applanation was $13 \& 15$ in her right and left eye, respectively. Eye movement were within normal limits in both eyes. Both eyes slit lamp examination of the anterior segment and vitreous was normal with no cells or haze. Dilated fundus examination revealed multiple yellow subretinal choroidal tubercles (Figure-1). Fluorescein angiography showed hyperfluorescence of tubercles in the arteriovenous phase (Figure-2). 

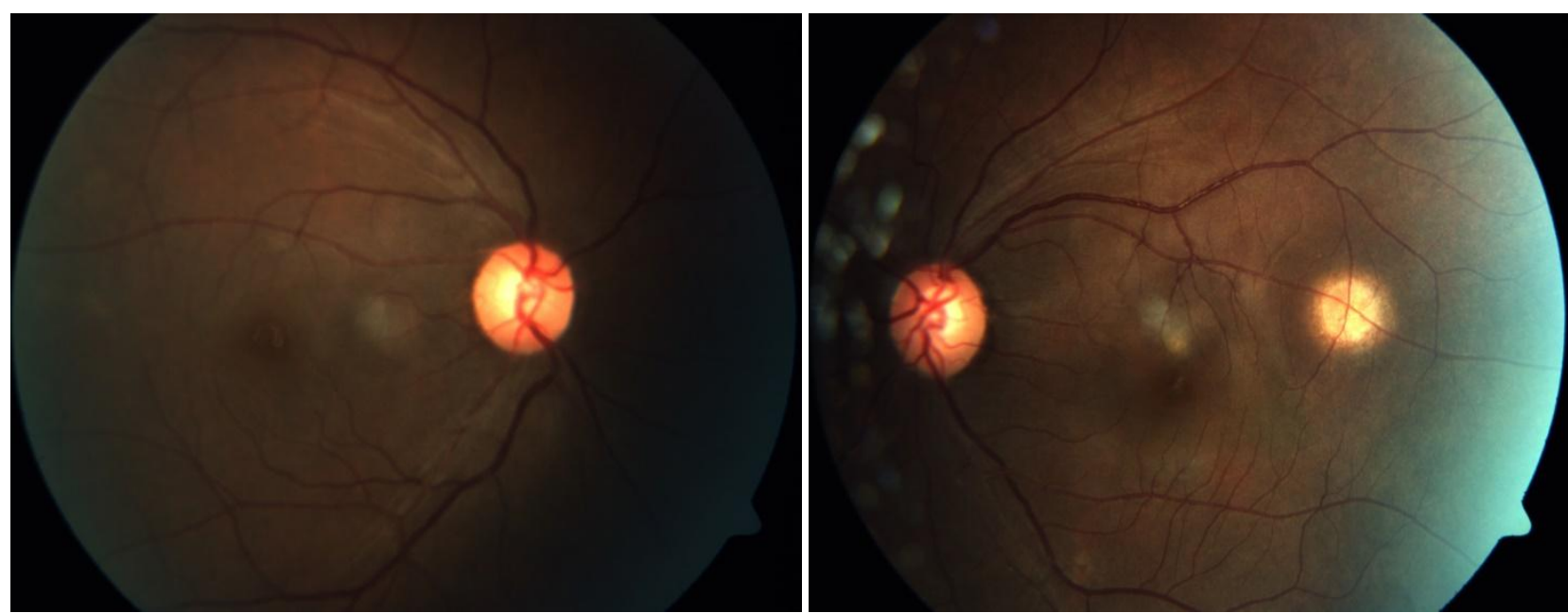

Fig-1: Fundus photo of Right eye \& left eye showing subretinal choroidal tubercles
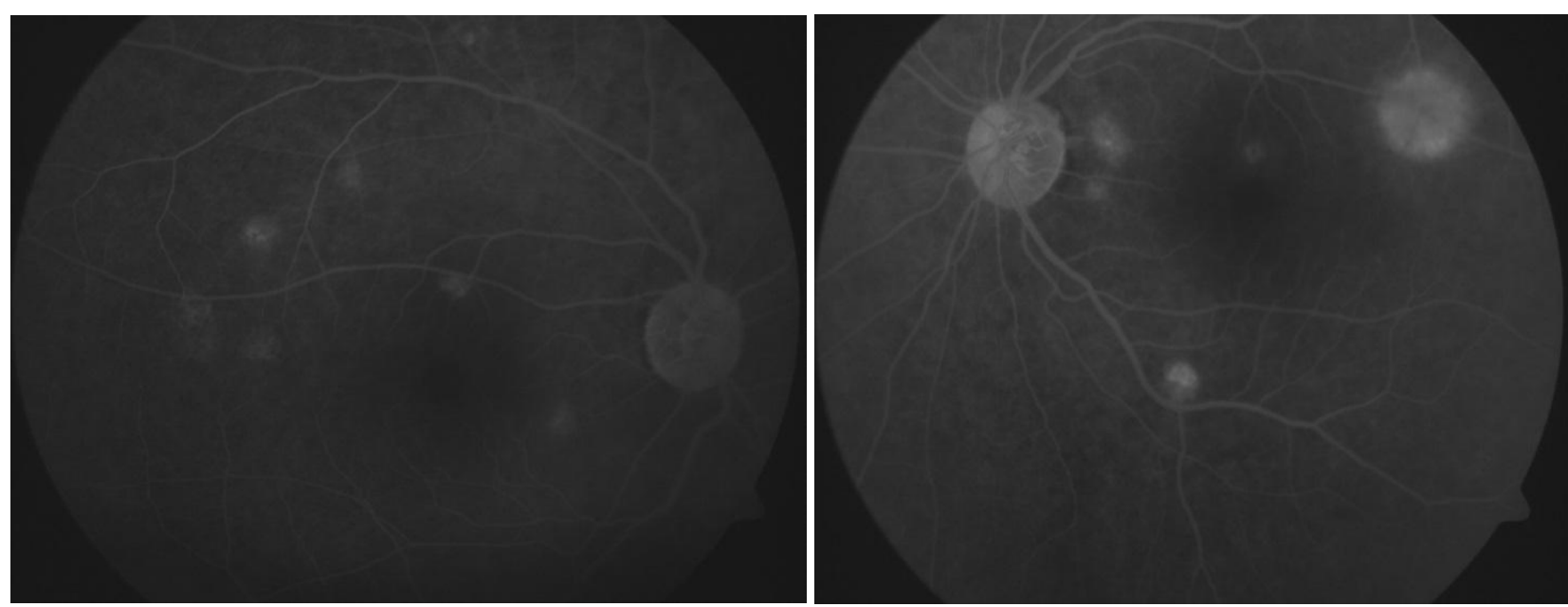

Fig-2: Fundus fluorescein angiography showing hyperfluorescence of tubercles in the arteriovenous phase

Investigations, from prior admission, are as follows. Hb-12.9, TC-8640, platelet count-195000, ESR-35 mm. RFT, LFT and serum electrolytes were within normal limits. MRI brain (plain\&contrast) was normal. CSF analysis showed opening pressure $240 \mathrm{cmH} 2 \mathrm{O}$, protein $482 \mathrm{mg} / \mathrm{dl}$, Sugar $54 \mathrm{mg} / \mathrm{dl}$ (Blood sugar $127 \mathrm{mg} / \mathrm{dl}$ ), ADA-44 IU/mL, cell count of 150 cell with $30 \%$ neutrophils and $70 \%$ lymphocytes. Sputum AFB and HIV were negative. Chest X-ray, USG Abdomen and HRCT Thorax were normal. EEG recording showed generalized slowing of background activity. CSF MTB PCR report by real-time polymerase chain reaction (RT-PCR) kit was negative for tuberculosis DNA. On the basis of clinical and CSF examination, patient was diagnosed as tuberculous meningitis. Management with five drug anti-tubercular treatment with isoniazid, ethambutol, pyrazinamide, rifampicin and streptomycin was done. This was supplemented with steroids, antiepileptic, antipyretic, pyridoxine and calcium supplements.

Patient's fundus and angiography findings were consistent with choroidal tubercles. She was continued on anti-tubercular therapy and oral steroids and local steroid in form of posterior subtenon injection was given in left eye to which she responded. There was significant improvement in vision to $6 / 9$ with N6 in the left eye on second followup after 14 days. On examination, the choroidal tubercules was found to have completely resolved. She was advised to continue antitubercular therapy with tapering doses of oral steroid.

\section{DiscuSSION}

Choroidal tuberculosis is the most common initial manifestation of intraocular tuberculosis. They may be seen in $1.4 \%$ to $60 \%$ of patients with different forms of tuberculosis [5, 6]. Miliary tuberculosis accounts for about less than $2 \%$ of all cases of tuberculosis and results from acute hematogenous spread of tubercular bacilli. Choroid tubercles often appears early in the course of illness, when present, they are pathognomonic of milliary tuberculosis [7]. However, infrequently choroidal tubercles may be associated with pulmonary or extrapulmonary tuberculosis [3] as in our case tuberculous meningitis. A history of tuberculous meningitis with normal HRCT and no systemic involvement, confirmed on clinical examination and investigation, fundus findings, angiography and response to treatment led to the 
diagnosis of our patient. Therefore, ophthalmoscopic examination should be recommended in all patients of tuberculosis. A high degree of clinical suspicion is important for its diagnosis as delay in treatment may lead to irreversible visual loss.

\section{Conclusion}

Choroidal tubercles considered highly specific for miliary tuberculosis, may occur in isolated tuberculous meningitis. Early detection of choroidal inflammation and timely management can prevent visual loss as the ocular lesion resolves completely.

\section{REFERENCES}

1. Donahue HC. Ophthalmologic experience in a tuberculosis sanatorium. Am J Ophthalmol; 1967;64:742-748.
2. Tabbara KF. Ocular tuberculosis: anterior segment. Int Ophthalmol Clin, 2002; 45:57-69.

3. Tejada P, Mendez MJ, Negreira S. Choroid tubercles in tuberculous meningitis. Int Ophthalmol, 1994;18(2):115-8.

4. Oommen TT, Mallesh P, Ramaiah M, Thayyil AA, Narayanagowda L. Choroidal tubercles in isolated tuberculous meningitis. Journal of Evolution of Medical and Dental Sciences. 2016 Apr 25;5(33):1858-60.

5. Biswas J, Badrinath SS. Ocular morbidity in patients with active systemic tuberculosis. Int Ophthalmol, 1995-1996;19:293-8.

6. Illingworth RS, Lorber J. Tubercles of the choroid. Arch Dis Child, 1956;31:467-9.

7. Rodin FH, Dickey LB. Tubercle of the choroid in milliary tuberculosis: case report. California and Western Medicine, 1928;28(6):807-809. 